http://jmscr.igmpublication.org/home/ ISSN (e)-2347-176x ISSN (p) 2455-0450 crossref DOI: https://dx.doi.org/10.18535/jmscr/v8i1.36

Journal Of Medical Science And Clinical Research

\title{
A Study of Type - I Tympanoplasty in Tympanosclerosis of Tympanic Membrane with Central Perforation
}

\author{
Dr Niharika Muddada ${ }^{1}$, Dr S. Surya Prakasa Rao ${ }^{2 *}$, Dr T.V.S.S.N. Leela Prasad ${ }^{3}$, \\ Dr K.V. Madhavi Latha \\ ${ }^{1}$ Junior Resident of ENT, Andhra Medical College, Visakhapatnam, India \\ ${ }^{2}$ Professor of ENT, Andhra Medical College, Visakhapatnam, India \\ ${ }^{3}$ Assistant Professor of ENT, Andhra Medical College, Visakhapatnam, India \\ ${ }^{4}$ Senior Consultant, Gynaecologist, Visakhapatnam, India \\ *Corresponding Author \\ Dr S. Surya Prakasa Rao \\ Professor of ENT, Andhra Medical College, Visakhapatnam, Andhra Pradesh, India
}

\begin{abstract}
Background: Tympanosclerosis is a common sequela of chronic otitis media found in all age groups, and it is the irreversible terminal stage of a pathological process based on the inflammation of middle ear mucosa, which was not regressed to restitution and integrum and which does not continue as an inflammatory process.
\end{abstract}

However, in spite of its inertness, it is a major clinicopathological thing as it may result in a rigidity of the sound conducting mechanism of the ear.

Aim: In the present study, the aim is to study Type - I tympanoplasty in tympanosclerosis patients in regards to their clinical presentation and graft uptake and hearing improvement by different techniques.

1. Underlay graft by removing only tympanosclerotic plaques leaving remnants of the tympanic membrane

2. Underlay graft by removing both tympanosclerotic plaques and remnants by making into a subtotal central perforation.

3. Underlay graft without removing tympanosclerotic plaques.

Materials and Methods: The material is chiefly from those patients who attended the outpatient department of government ENT hospital, Visakhapatnam with a history of decreased hearing, ear discharge. 60 cases of tympanosclerosis were selected and studied for a period of 18 months, i.e., from August 2017 to January 2019.

Results: This study showed that slight female preponderance with female: male 1.30 : 1 ; Out of 60 patients in the study group most common age group being 25-40 years. Results of the surgical procedure were good, with graft taken up well in all the cases of Group $-A$ whereas in one case residual central perforation noted in Group $-B$ and one case in Group $-C$ with no significant difference seen in the hearing improvement with the presence of the tympanosclerotic plaque unless it is present at a site with some fixity of the sound conducting mechanism.

Conclusion: Tympanosclerosis is associated with a predominantly conductive type of hearing loss. Hearing loss can be alleviated to a greater extent in a majority of patients by an appropriate surgery.

Keywords: Tympanosclerosis, Tympanosclerotic plaques, Tympanoplasty. 


\section{Introduction}

It is the term used to describe a histological abnormality that occurs in the middle ear mucosa (ME) or mastoid characterized by hyalinization, which may progress to calcification or ossification, which was named as Tympanosclerosis ${ }^{1}$. It was first described by Von Tröltsch, in 1873, who reported a pathological process characterized by ME mucosa rigidity ${ }^{2}$. Later, Zöllner; Beck, in the year 1955, introduced the term tympanosclerosis. ${ }^{3}$ It is the terminal stage of a disease process originated from acute, chronic or recurrent inflammation of ME lamina propria, characterized by progressive infiltrate of fibroblasts, causing an increase in collagen, which initiates poor formation of cells and blood vessels, followed by hyaline degeneration and in some occasions, calcium deposits ${ }^{1,4}$, which may lead to formation of cartilage or bone ${ }^{8}$. In a few cases, there may be functional damage for the tympanicossicle unit, causing conductive hearing loss, which affects surgical decisions during tympanoplasties.

Although the pathogenesis is not yet clear, a prerequisite appears to be Chronic otitis media followed by the process of healing. Tympanosclerosis though a relatively benign condition, causes a conductive type of hearing loss predominantly. But this loss usually depends on the extent of the tympanosclerotic plaques and their location. However, the exact extent of tympanosclerosis can be judged only after formal exploration of the middle ear, and it is its only definitive treatment.

\section{Aim}

The aim of the present study is to study Type - I tympanoplasty in tympanosclerosis patients in regards to their clinical presentation and graft uptake and hearing improvement by different techniques.

1. Underlay graft by removing only tympanosclerotic plaques leaving remnants of the tympanic membrane
2. Underlay graft by removing both tympanosclerotic plaques and remnants by making into a subtotal central perforation.

3. Underlay graft without removing tympanosclerotic plaques.

\section{Materials and Methods}

The present study was conducted at Department of ENT, Government ENT Hospital, Andhra medical college, Visakhapatnam, from August 2017 to January 2019. The study group includes 60 cases who attended the outpatient department of government ENT hospital; Visakhapatnam was selected recorded and followed - up for a period of 18 months. Type - I tympanoplasty is the surgical procedure done in all the cases by underlay technique. Out of 60 cases in the study group , in Group - A 20 cases were operated by completely removing the tympanosclerotic plaque by leaving a rim of remant of tympanic membrane, in Group - B 20 cases were operated by removing both the tympanosclerotic plaque and remnants and making it into a subtotal central perforation, whereas in Group - C 20 cases were operated without removing tympanosclerotic plaque. Post operative instructions given. Patients were followed up for 6 months to study the graft uptake and to assess hearing improvement.

\section{Inclusion Criteria}

1) Males and females in the age group ranging from 15-60yrs.

2) Patients with tympanosclerotic plaques with central perforation were included in the study.

\section{Exclusion Criteria}

1) Patients who did not give consent for the study.

2) Patients with Previous otologic surgery

3) Patients having any congenital ear anomalies

4) Patients with sensori neural hearing loss.

5) Patients with CSOM with intra cranial complications 
6) Patients with CSOM with aural polypi, granulations and attic disease

7) Patients with CSOM with otosclerosis.

\section{Results}

\section{Age Wise Distribution}

\begin{tabular}{|c|c|c|}
\hline AGE (in years) & NO.OF CASES & PERCENTAGE \\
\hline $15-25$ & 6 & $10 \%$ \\
\hline $25-40$ & 48 & $80 \%$ \\
\hline $40-60$ & 6 & $10 \%$ \\
\hline Total & 60 & $100 \%$ \\
\hline
\end{tabular}

\section{Gender Distribution}

\begin{tabular}{|l|c|c|}
\hline MALES & FEMALES & TOTAL \\
\hline $26(43 \%)$ & $34(57 \%)$ & $60(100 \%)$ \\
\hline
\end{tabular}

\section{Incidence of Presenting Complaints}

\begin{tabular}{|l|c|c|}
\hline $\begin{array}{l}\text { PRESENTING } \\
\text { COMPLAINT }\end{array}$ & $\begin{array}{c}\text { NO. OF } \\
\text { CASES }\end{array}$ & PERCENTAGE \\
\hline DEAFNESS & 40 & $67 \%$ \\
\hline EAR DISCHARGE & 13 & $22 \%$ \\
\hline $\begin{array}{l}\text { NON-OTOLOGICAL } \\
\text { COMPLAINTS }\end{array}$ & 7 & $11 \%$ \\
\hline TOTAL & 60 & $100 \%$ \\
\hline
\end{tabular}

\section{Site of Predilection of Tympanosclerotic Plaque}

\begin{tabular}{|l|c|c|}
\hline $\begin{array}{l}\text { SITE-OF TYMPANOSCLEROTIC } \\
\text { PLAQUE }\end{array}$ & $\begin{array}{c}\text { NO.OF } \\
\text { CASES }\end{array}$ & PERCENTAGE \\
\hline POSTERO - SUPERIOR & 36 & $60 \%$ \\
\hline ANTERO - INFERIOR & 12 & $20 \%$ \\
\hline POSTERO - INFERIOR & 6 & $10 \%$ \\
\hline ANTERO - SUPERIOR & 6 & $10 \%$ \\
\hline TOTAL & 60 & $100 \%$ \\
\hline
\end{tabular}

\section{Pre - OP Hearing Thresholds}

\begin{tabular}{|l|c|c|}
\hline $\begin{array}{l}\text { PRE- OP PTA } \\
(\mathrm{dB})\end{array}$ & $\begin{array}{c}\text { NO.OF } \\
\text { PATIENTS }\end{array}$ & PERCENTAGE \\
\hline $26-32$ & 25 & $42 \%$ \\
\hline $33-40$ & 35 & $58 \%$ \\
\hline TOTAL & 60 & $100 \%$ \\
\hline
\end{tabular}

\section{Graft Uptake}

\begin{tabular}{|l|c|c|c|}
\hline GROUPS & $\begin{array}{c}\text { No.of } \\
\text { cases }\end{array}$ & $\begin{array}{c}\text { Taken up } \\
\text { well }\end{array}$ & $\begin{array}{c}\text { Residual central } \\
\text { perforation }\end{array}$ \\
\hline A & 20 & 20 & - \\
\hline B & 20 & 19 & 1 \\
\hline C & 20 & 19 & 1 \\
\hline Total & 60 & 58 & 2 \\
\hline
\end{tabular}

\section{Hearing Improvement}

\begin{tabular}{|l|c|c|c|c|}
\hline $\begin{array}{l}\text { Tympanosclerosis } \\
\text { groups }\end{array}$ & $\begin{array}{c}\text { No.of } \\
\text { cases }\end{array}$ & $\begin{array}{c}\text { Pre - op hearing } \\
\text { thresholds(PTA) } \\
\text { mean +/-SD }\end{array}$ & $\begin{array}{c}\text { Post - op } \\
\text { hearing } \\
\text { thresholds(PTA) } \\
\text { mean +/-SD }\end{array}$ & $\begin{array}{c}\text { Net hearing } \\
\text { gain } \\
\text { (decibels) } \\
\text { dB }\end{array}$ \\
\hline Group - A & 20 & $38+/-3.82$ & $19+/-2.49$ & $19+/-2.00$ \\
\hline Group - B & 20 & $40+/-6.71$ & $19+/-4.34$ & $21+/-3.64$ \\
\hline Group - C & 20 & $36+/-4.85$ & $21+/-3.70$ & $15+/-2.98$ \\
\hline
\end{tabular}

\section{Discussion}

According to the present study, the sex distribution between females and males 1.30:1. There was slight female preponderance.

Out of the total 60 cases in the study group, the maximum no. of cases noted in $25-40$ years of age group. Bhaya et al. ${ }^{9}$ and Yabe et al. had reported a male to female ratio of 1.6:1 and 1.8:1, respectively, whereas in a study conducted by Pal et $\mathrm{al}^{11}$. Had described the ratio to be roughly $1: 1$. This variation in the data was said to be due to the extremely random selection of patients in various studies.

In a study conducted by Hatem S. Badran et.al ${ }^{10}$, the average age range was 16 to 47 years.

In the present study, the most typical presenting symptom was deafness of varying degrees with most frequent being the conductive hearing loss noted in $67 \%$ i.e, in 40 cases Pal et al. ${ }^{11}$ in their series had found that about $60 \%$ of their cases had deafness as their presenting complaint, of which $83.3 \%$ had a conductive loss. The impairment of hearing was due to the involvement of the middle ear conductive system due to the inflammatory process leading to tympanosclerosis (Sorensen \& True, 1978).

In a study conducted by Ameya Asarkar and Shishir Gosavi ${ }^{12}$ out of 73 cases, only 2 cases showed pure sensorineural hearing loss, and 9 cases had mixed hearing loss.

Gibb et al. ${ }^{13}$ had suggested that sensorineural hearing loss may occur due to the involvement of the inner ear by tympanosclerosis.

In the present study, ear discharge was reported in 13 cases out of 60 cases. In a study conducted by Ameya Asarkar and Shishir Gosavi ${ }^{12}$, ear discharge was seen in only 4 out of the 73 cases of tympanosclerosis, making it only $5.5 \%$ of the cases. Asiri et al. ${ }^{14}$ in, their series had found ear discharge as a chief complaint in only 13 of 90 cases.

In the present study, the most commonly involved Site of predilection of tympanosclerotic plaque was found to be the posterosuperior quadrant of the pars tensa, followed by anteroinferior quadrant 
and posteroinferior and anterosuperior quadrants. The pars flaccida was not involved in any of the cases of tympanosclerosis.

Various studies have stated different findings concerning the site of involvement by tympanosclerotic plaque. Bhaya et $\mathrm{al}^{9}$ reported the anteroinferior and posteroinferior quadrants to be the most frequently involved. Whereas in a study conducted by Yabe et al., it was the anterosuperior and posteroinferior quadrants of the pars tensa.According to Jaisinghani ${ }^{15}$, it was the anteroinferior quadrant.

According to Sade and Tos and Bak Pedersen ${ }^{16}$, tympanosclerotic plaques occur in the region where the number of mucous glands is low, and the ciliary activity is least noticed. Thus the stagnation of inflammatory exudates is favored. The head of the malleus and the body of incus both accommodated in the attic are the most common sites in the middle ear, which are mainly affected by tympanosclerosis, and this being the important cause of the higher degree seen when the middle ear is involved.

Surgical exploration revealed the extent of involvement of the middle ear by tympanosclerosis. According to Gibb, ${ }^{13}$ the tympanosclerotic plaques are characteristic in the epitympanum and in relation to the malleus. $\mathrm{Kamal}^{17}$ reported that in the middle ear cavity tympanosclerotic plaques commonly affect the ear drum,promontory, the oval window niche, ossicular chain and the facial nerve.

In a study conducted by Ameya Asarkar and Shishir Gosavi ${ }^{12}$ The uptake of graft was seen in 54 cases undergoing Type 1 Tympanoplasty of 57 patients $(94.7 \%)$ who underwent the surgery. graft uptake rate in cases; where tympanosclerotic plaques were completely removed was $95.6 \%$ and it was $91 \%$ in those cases where tympanosclerotic plaques were either partially removed or left as such.

In the present study the graft uptake was seen in 58 cases $(96.6 \%)$ and residual central perforation noted in 2 cases $(3.33 \%)$ post operatively the grafts were taken up well in almost all cases in
Group - A , whereas one case of residual central perforation noted in Group - B and one case of residual central perforation noted in Group - $\mathrm{C}$.

In a study conducted by Ameya Asarkar and Shishir Gosavi ${ }^{12}$ in patients with tympanosclerotic plaques completely removed from the tympanic membrane the pre operative pure tone audiogram is $35.95+/-12.37$ and the post operative pure tone audiogram is $26.70+/-10.17$. whereas in patients with tympanosclerotic plaques removed partially from the tympanic membrane the pre operative pure tone audiogram is $38.36+/-9.62$ and the post operative pure tone audiogram is $28.55+/-7.64$.

There was hearing improvement noted in majority of the cases in the study group, however there is a difference in net hearing gain i.e, significant hearing improvement noted mainly in group - A and group $-\mathrm{B}$ while compared with group $-\mathrm{C}$.

Thus the overall results of surgery in ears with tympanosclerosis is good, both in terms of graft uptake and in terms of hearing improvement.

Moreover plaque removal risks tearing of the tympanic membrane and enlarges the perforation . Wielinga et al, santos et al however had reported poor functional results in those cases.

Histopathology of the plaques after haematoxylin and eosin staining revealed dense bundles of collagen hyaline degeneration and scattered areas of calcification.

\section{Conclusion}

Tympanosclerosis is a clinicopathological entity most commonly seen in Chronic otitis media with central perforation.

It can affect almost any part of the middle ear cleft and is often asymptomatic but may be an accidental finding in otologically asymptomatic patients.

There is a slight female preponderance with female : male $1.30: 1$.

Tympanosclerosis is associated predominantly with a conductive type of hearing loss.

Hearing loss can be alleviated to a greater extent in a majority of patients by an appropriate surgery. 
Results of the surgery are good and not affected by the presence of the plaque unless it is present at a site with some fixity of the sound conducting mechanism.

\section{References}

1. House WF, Sheehy JL. Tympanosclerosis. Archives of Otolaryngology 1960; 72: 3843.

2. Von Tröltsch AF. Lehrbuch der Ohrenheilkunde. F.G.M. Vogel. Leipzig; 1873.

3. Zöllner F \& Beck C. Die Paukensclerose. Laryng Rhinol Otol 1955; 34: 137-55.

4. Zöllner F.Tympanosclerosis. Arch Otolaryng (Chic.)1963; 78: 53844.

5. Brockman SJ. Problems encountered in tympanoplastic surgery. Laryngoscope 1961; 71: 859-66.

6. Joseph RB, Gordon J. Tympanosclerosis. Arch Otolaryngol 1963; 77: 186-90.

7. Igarashi $\mathrm{M}$, Konishi S, Alford BR, Guilford FR. The pathology of tympanosclerosis. Laryngoscope 1970; 80: 233-43.

8. Schuknecht HF. Pathology of ear. Cambridge, M.A: Harvard University Press; 1974.

9. Bhaya, MH, Schachern, PA Morizono T, Paparella MM. Pathogenesis of tympanosclerosis. Otolaryngol -Head Neck Surg 1993;109:413-20.

10. Hatem S. Badran ,Hazem M. Abdel Tawab, Basim M. Wahba, Khairy M. Abulnasr Myringosclerosis with Chronic Safe Suppurative Otitis Media: Hearing Outcome after Surgical Management According to Myringosclerotic Patch Site and Inclusion in the Surgery - Int Adv Otol 2014; 10(3): 260-3

DOI: 10.5152/iao.2014.467.

11. Pal Indranil, Sengupta A (2005) Clinicopathological and audiological study of tympanosclerosis Indian Journal of Otolaryngology 57: 235-239.
12. Ameya Asarkar and Shishir Gosavi Tympanosclerosis - a Beginner's Worry: a Case Series and Review of Literature Otolaryngology 2013, Vol 3(2): 133 DOI: 10.4172/2161-119X.1000133.

13. Gibb AG. Tympanosclerosis. Acta Otolrhinol Belgiga 1971;25:956.

14. 14. Saad Asiria, Alaa Hashama, Fatma A Anazy, Siraj Zakzouka, and Adel Banjar (1999) Tympanosclerosis: Review of literature and incidence among patients with a middle ear infection. Journal of Laryngology and Otology 113: 1076-1080.

15. Jaishinghani VJ, Hunter LL, Li Y, Margolis RH. Quantitative analysis of tympanic membrane disease using videootoscopy. Laryngoscope 2000;110:172630.

16. Ferlito A. Pathologia del Otomastoidite Purulenta Cronica. AttiDell' Accademia Nazionale dei Lince, S VIII, 1974;12:53.

17. Kamal SA. Surgery of tympanosclerosis. J Laryngol Otol 1997;111:917- 23. 